\title{
Rekonfigurasi Saluran Distribusi 20 kV Untuk Mengurangi Rugi-Rugi Daya dan Jatuh Tegangan Pada Penyulang Abang
}

\author{
I Putu Arya Suardika ${ }^{1}$, I Gede Dyana Arjana ${ }^{2}$, Anak Agung Gede Maharta Pemayun ${ }^{3}$ \\ Program Studi Teknik Elektro, Fakultas Teknik, Universitas Udayana Denpasar - Bali \\ Email : putuarya.suardika@gmail.com ${ }^{1}$, dyanaarjana@unud.ac.id ${ }^{2}$, maharta@unud.ac.id $^{3}$
}

\begin{abstract}
Abstrak
Penyulang Abang merupakan salah satu dari empat puluh satu penyulang di Area Kerja PT PLN (Persero) Area Bali Timur. Penyulang ini menggunakan konfigurasi tipe radial yang melayani konsumen yang berada pada daerah Padangkerta, Bias, Batannyuh, Kikian, Ababi, Kebon, Abang, Datah, Kubu, Nusu, Tianyar, dan Ban. Penyulang ini mempunyai panjang saluran yang mencapai $212,8 \mathrm{kms}$ dengan total gardu distribusi sebanyak 167 unit trafo dan beban puncak penyulang ini mencapai $5.669 \mathrm{~kW}$. Kondisi ini mengakibatkan terjadinya jatuh tegangan sebesar 16,255\% dan rugirugi daya sebesar $10,12 \%$. Rekonfigurasi penyulang ini dilakukan dengan dua cara yaitu pemotongan jaringan yang dialihkan ke penyulang Subagan dan perencanaan penyulang Kubu. Rekonfigurasi dengan pemotongan jaringan memperlihatkan perbaikan tegangan penyulang Abang yang awalnya jatuh tegangannya sebesar $16,255 \%$ menjadi $3,05 \%$ dan penurunan rugi-rugi daya yang awalnya $10,12 \%$ menjadi $3,49 \%$. Perbaikan tegangan dan rugi-rugi daya yang terjadi pada penyulang ini tidak diikuti oleh penyulang Subagan. yang mengalami kenaikan persentase jatuh tegangan yang awalnya sebesar $6,78 \%$ menjadi $27,615 \%$ dan rugi-rugi dayanya yang awalnya sebesar 3,89\% menjadi $13,28 \%$. Sementara rekonfigurasi dengan perencanaan penyulang Kubu mampu memperbaiki jatuh tegangan penyulang Abang menjadi 2,94\% dan rugi-rugi dayanya menjadi 3,41\%. Sedangkan, penyulang Kubu sesuai dengan hasil running program ETAP jatuh tegangannya sebesar 2,95\% dan rugi-rugi daya sebesar 2,73\%.
\end{abstract}

Kata Kunci : Penyulang Abang, Rekonfigurasi, Jatuh Tegangan, Rugi-Rugi Daya

\begin{abstract}
The feeder of Abang is one of forty-one feeders in State Electrical Company (PT PLN) of east Bali Area. This feeder uses a configuration of radial type that serves consumers in the area of Padangkerta, Bias, Batannyuh, Kikian, Ababi, Datah, Kubu, Nusu, Tianyar and Ban. It has a line transect that is 212,8 kms in leght with a total of distribution subtatations of 167 transformers and its peaks load reaches $5669 \mathrm{~kW}$. This conditions results in drop voltage of 16,255\% and and power losses of 10,12\%. Feeder reconfiguration is accomplished by two ways: the cutting of the network that is diverted to Subagan feeder and the planning of Kubu feeder. Reconfiguration by using a method of cutting the network shows a voltage correction of Abang feeder with the initial drop voltage of 16,255\% to $3.05 \%$ and the initial power losses of $10,12 \%$ to $3,49 \%$. The improvement of voltage and power losses occurring in this feeder is not followed by Subagan feeder, which experienced an initial rise in the percentage of drops voltage of $6,78 \%$ to $27,615 \%$ and its initial power losses of $3,89 \%$ to $13,28 \%$. While reconfiguration with Kubu's feeder planning is able to repair the drop voltage of Abang feeder to $2.94 \%$ and its power losses to 3,41\%. Meanwhile, Kubu's feeder in accordance with the results of running the program ETAP that the value of drop voltage is 2,95\% and power losses is 2,73\%.

Keywords: Feeder, Reconfiguration, Drop Voltage, Power Loss

1. PENDAHULUAN

Kebutuhan tenaga listrik terus mengalami peningkatan seiring dengan tuntutan hidup yang tidak dapat dipisahkan untuk menunjang segala aktivitas sehari-hari. Pesatnya perkembangan pembangunan diiring dengan kenaikan beban dan panjang saluran. Peningkatan beban akan mengakibatkan

terjadinya perluasan jaringan. PT PLN (Persero) Area Bali Timur merupakan unit bisnis PT PLN (Persero) Distribusi Bali yang mempunyai tugas pokok untuk menjaga kehandalan serta kualitas dari sistem tenaga listrik di area kerja Bali bagian timur. Penyulang Abang merupakan sistem distribusi $20 \mathrm{kV}$ yang disuplai dari gardu induk Amlapura
\end{abstract}


trafo II/30 MVA. Penyulang ini adalah penyulang terpanjang di Area Bali Timur dengan panjang salurannya yaitu $212,8 \mathrm{~km}$ dan panjang saluran utama sejauh $72,9 \mathrm{~km}$. Saluran distribusi yang panjang mengakibatkan terjadinya jatuh tegangan pada ujung jaringan dan rugi-rugi daya yang besar sehingga kualitas energi listrik yang disalurkan ke konsumen baik pelanggan TR maupun pelanggan TM menjadi kurang baik. Sesuai dengan SPLN No.72 Tahun 1987 yaitu adanya batas toleransi tegangan sebesar $+5 \%$ dan $10 \%$.

Meningkatnya kebutuhan tenaga listrik, sebaiknya diimbangi dengan kualitas tegangannya. Kualitas tegangan dan efisiensi energi listrik sangat dipengauhi oleh jatuh tegangan dan rugi-rugi daya listrik. Besarnya rugi-rugi daya dan jatuh tegangan pada saluran distribusi tergantung pada jenis dan panjang penghantar, tipe jaringan distribusi, kapasitas trafo, tipe beban, faktor daya, dan besarnya jumlah daya terpasang serta banyaknya pemakaian beban-beban yang bersifat induktif yang menyebabkan meningkatnya kebutuhan daya reaktif. Mengurangi rugi-rugi daya dan jatuh tegangan dapat dilakukan dengan berbagai cara seperti penambahan kapasitor bank, memperbesar luas penampang penghanta dan melakukan perubahan kembali sistem dengan cara rekonfigurasi sistem [1].

Kawasan Abang, Tianyar dan sekitarnya saat ini disuplai oleh penyulang Abang. Sebelum dilakukan rekonfigurasi jaringan, penyulang ini berbentuk konfigurasi jaringan distribusi $20 \mathrm{kV}$ tipe radial. Berdasarkan data PT PLN (Persero) Area Bali Timur, tercatat jumlah pelanggan penyulang Abang sebanyak 23.614 pelanggan TR dan 2 pelanggan TM, 167 unit transformator, dan total daya 5.669 kW. Rugi-rugi daya pada penyulang Abang sebesar $573,7 \mathrm{~kW}$ atau $10,12 \%$ dan untuk tegangan terendah pada penyulang Abang mencapai 16,749 kV atau terjadi jatuh tegangan sebesar 16,255\%. Sebagian besar pelanggan tersebut merupakan pelanggan dengan kategori umum (rumah tangga). Penyulang Abang memiliki panjang saluran $212,8 \mathrm{~km}$ dan panjang saluran utamanya 72,9 $\mathrm{km}$. Saluran yang panjang diakibatkan oleh kondisi geografis pada lahan persawahan yang luas dan hutan-hutan. Penyulang Abang berdekatan dengan penyulang Subagan dan penyulang Candra Buana.
Berdasarkan permasalahan di atas maka dapat dianalisa rekonfigurasi penyulang Abang dengan tujuan untuk menurunkan jatuh tegangan dan rugi-rugi daya pada wilayah Padangkerta, Bias, Batanyuh, Kikian, Ababi, Kebon, Abang, Datah, Kubu, Nusu, Tianyar, dan Ban menggunakan software ETAP. Rekonfigurasi saluran distribusi dilakukan dengan melakukan pemotongan jaringan sebagian beban pada penyulang Abang dan dialihkan ke penyulang-penyulang yang berdekatan dengan penyulang Abang serta dilakukan pembangunan penyulang baru yang akan diberikan nama penyulang Kubu.

\section{KAJIAN PUSTAKA}

\subsection{Sistem Tenaga Listrik}

Pembangkit listrik pada umumnya terletak jauh dari pusat beban, terlebih pembangkit listrik berskala besar, sehingga untuk menyalurkan tenaga listrik tersebut sampai ke konsumen atau pusat beban maka tenaga listrik tersebut harus disalurkan. Secara garis besar sistem tenaga listrik dapat digambarkan seperti Gambar 1 [2]

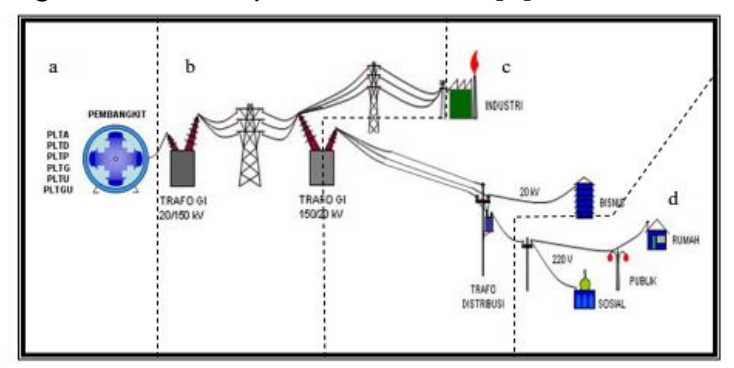

Gambar 1. Sistem Tenaga Listrik

\subsection{Sistem Distribusi Primer}

Sistem distribusi primer atau sering disebut jaringan distribusi tegangan menengah terletak diantara gardu induk dengan gardu pembagi atau gardu distribusi yang memiliki tegangan sistem lebih tinggi dari tegangan untuk konsumen. Standar tegangan untuk jaringan distribusi primer ini adalah $6 \mathrm{kV}, 10$ $\mathrm{kV}$, dan $20 \mathrm{kV}$. [3]

\subsection{Sistem Distribusi Radial}

Sistem distribusi tipe radial merupakan sebuah sistem yang hanya terhubung ke satu sumber dan antara titik sumber dan titik bebannya hanya terdapat satu saluran (line), tidak ada alternatif saluran lainnya. Sistem distribusi radial dapat dilihat pada Gambar 2 [4] 


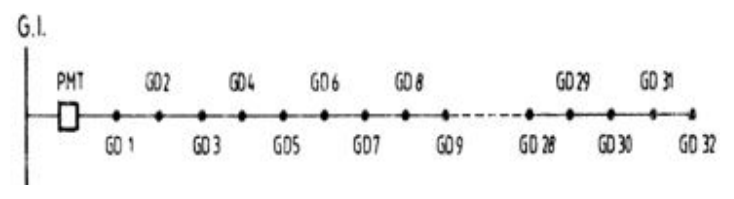

Gambar 2. Sistem Distribusi Radial

\subsection{Sistem Distribusi Ring / Loop}

Sistem distribusi ring / loop pada jaringan distribusi merupakan suatu sistem penyaluran melalui dua atau lebih saluran penyulang atau feeder yang saling berhubungan membentuk rangkaian berbentuk cincin (ring).Sistem distribusi ring/loop dapat dilihat pada Gambar 3

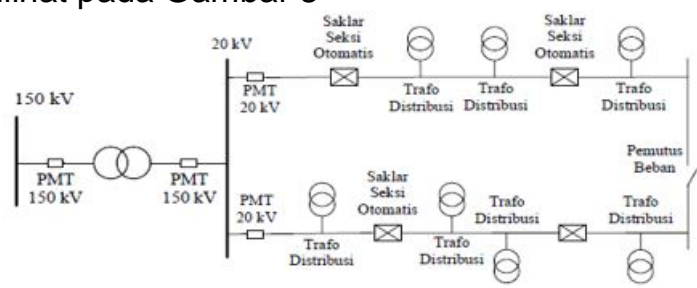

Gambar 3. Sistem Distribusi Ring/Loop

\subsection{Sistem Distribusi Spindel}

Konfigurasi spindel umumnya dipakai pada saluran kabel bawah tanah. Pada konfigurasi ini dikenal 2 jenis penyulang yaitu penyulang cadangan (stand-by atau express feeder) dan penyulang operasi (working feeder). Penyulang cadangan tidak dibebani dan berfungsi sebagai back-up supply jika terjadi gangguan pada penyulang operasi. Sistem distribusi spindel dapat dilihat pada Gambar 4 [5]

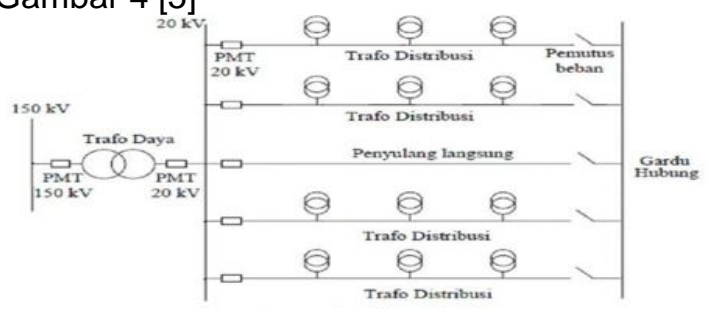

Gambar 4. Sistem Distribusi Spindel

\subsection{Sistem Distribusi Mesh}

Sistem distribusi mesh merupakan variasi dari sistem spindle. Perbedaannya hanyalah terletak pada bagian penyulang cadangan (express feeder). Pada sistem ini penyulang cadangan diberi beban seperti halnya penyulang kerja. Sistem ini mempunyai tingkat keandalan dan kontinuitas yang lebih baik dibandingkan dengan sistem disribusi loop. Sistem distribusi mesh dapat dilihat pada Gambar 5 [5]

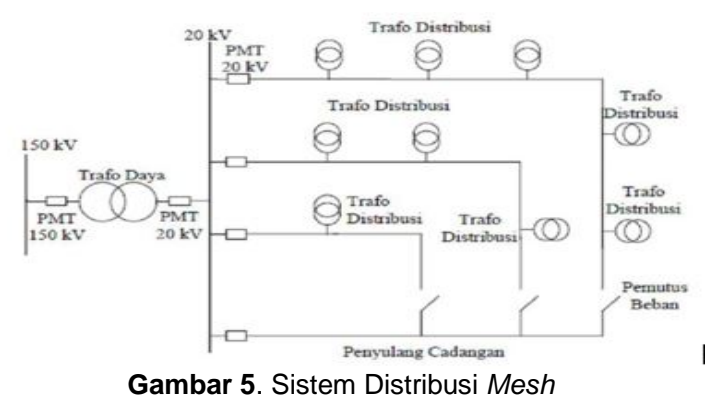

\subsection{Rugi-Rugi Daya}

Rugi-rugi daya adalah berkurang daya masukan yang terjadi pada suatu pengahantar atau kawat yang dilalui arus listrik. Kerugian daya dalam saluran listrik berbanding lurus terhadap panjang saluran dan beban, namun berbanding terbalik terhadap luas penampang saluran. Persamaan rugi-rugi daya dapat dituliskan sebagai berikut. [6]

$$
\Delta P=\left(\frac{P^{2}}{V^{2} \cdot \cos \varphi}\right) R
$$

dengan :

$\Delta \mathrm{P}$ adalah Rugi-Rugi Daya (W)

$V$ adalah Tegangan $(V)$

$\mathrm{R}$ adalah Hambatan Penghantar $(\Omega)$

$\cos \varphi$ adalah Faktor Daya

\subsection{Jatuh Tegangan}

Jatuh Tegangan merupakan selisih antara tegangan kirim dengan tegangan terima pada jaringan distribusi. Tegangan jatuh disebabkan oleh beberapa faktor yaitu arus, impedansi saluran dan jarak. Menghitung jatuh tegangan dapat digunakan rumus berikut [7]

dengan :

$$
V d=I(R \cos \varphi+X \sin \varphi)
$$

$\mathrm{Vd}$ adalah Voltage down $(\mathrm{V})$

I adalah Kuat Arus (A)

$\mathrm{R}$ adalah Resintasi Saluran $(\Omega / \mathrm{km})$

$\mathrm{X}$ adalah Reaktansi Saluran $(\Omega / \mathrm{km})$

\subsection{Rekonfigurasi Saluran Distribusi}

Rekonfigurasi saluran distribusi adalah suatu cara untuk mengatur ulang konfigurasi jaringan dengan jalan membuka dan menutup switch yang terdapat pada jaringan distribusi untuk mengurangi rugi-rugi daya pada jaringan distribusi atau untuk meningkatkan keandalan sistem distribusi sehingga efisiensi daya listrik yang disalurkan meningkat. [8]

\section{METODELOGI PENELITIAN}

Data yang digunakan dalam penelitian ini bersumber dari PT PLN (Persero) Area Bali 
Timur, PLN Rayon Karangasem dan studi literatur.

\subsection{Prosedur Penelitian}

Data yang digunakan dalam penelitian antara lain single line diagram penyulang Abang, data jenis penghantar,data panjang saluran, dan data jumlah beban.

Tahapan-tahapan yang dilakukan dalam penelitian adalah menganalisis aliran daya, mencari nilai jatuh tegangan dan rugi-rugi daya, melakukan rekonfigurasi penyulang dengan pemotongan saluran distribusi, melakukan rekonfigurasi penyulang Abang dengan pengoperasian penyulang Kubu dan melakukan simulasi menggunakan software.

\subsection{Alur Analisis}

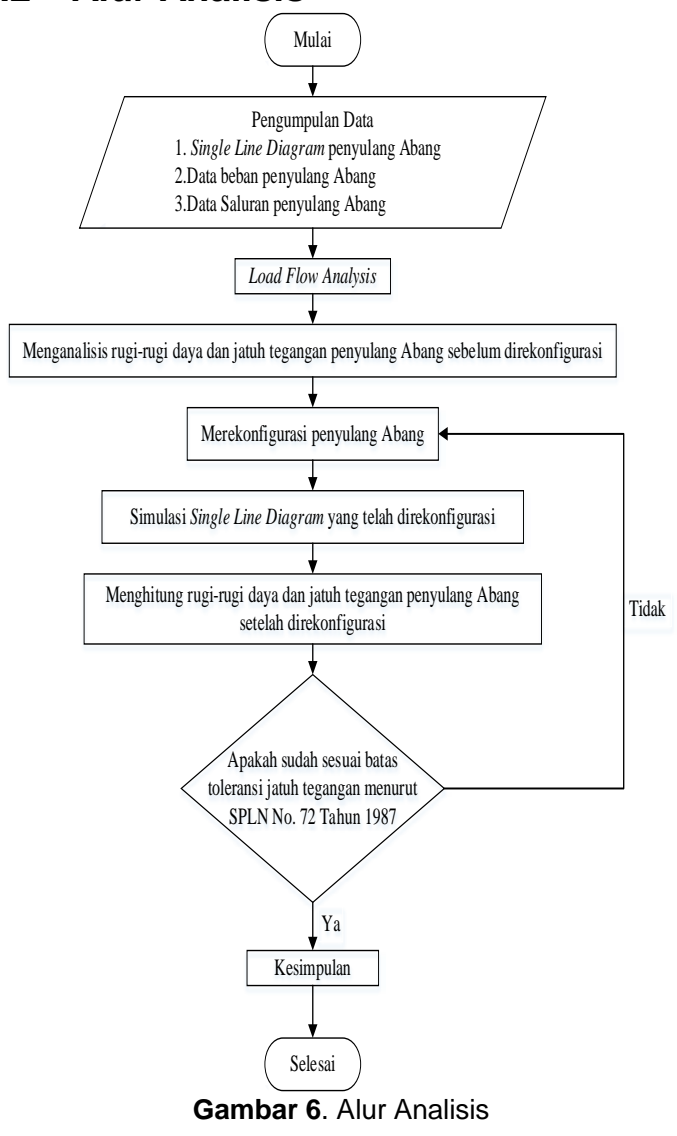

4. HASIL DAN PEMBAHASAN

\subsection{Jatuh Tegangan Penyulang Abang Sebelum Rekonfigurasi}

Jatuh tegangan Abang dapat dihitung dengan cara mengetahui besarnya daya terpasang dan arus maksimum yang mampu dipikul oleh penyulang Abang dengan besar tahanan dan reaktansi saluran jenis kawat AAAC $150 \mathrm{~mm}^{2}$. Perhitungan Jatuh tegangan penyulang menggunakan software ETAP dan diperoleh hasil untuk tegangan terendah sebesar 16,749 kV pada bus 237.

$$
\begin{aligned}
(\%) & =\frac{\text { Teg Sumber }- \text { Teg Terendah }}{\text { Teg Sumber }} \times 100 \% \\
& =\frac{20-16,749}{20} \times 100 \% \\
= & 16,255 \%
\end{aligned}
$$

\section{4,2 Rugi-Rugi Daya Penyulang Abang Sebelum Rekonfigurasi}

Analisa rugi-rugi daya pada penyulang Abang menggunakan software ETAP dengan memasukan data bus, data kapasitas trafo, data beban trafo, serta data penghantar. Hasil running program ETAP diperoleh rugi-rugi daya total sebesar $573,7 \mathrm{~kW}$.

$$
\begin{aligned}
\text { (\%) } & =\frac{\text { Rugi }- \text { Rugi Daya }}{\text { Daya Tersalurkan }} \times 100 \% \\
& =\frac{573,7}{5669} \times 100 \% \\
& =10.12 \%
\end{aligned}
$$

\subsection{Rekonfigurasi Penyulang Abang Dengan Pemotongan Jaringan}

Titik pertemuan penyulang Abang dengan penyulang Subagan terletak pada LBS Culik dengan posisi NO (normally open). Pemotongan jaringan dilakukan secara offline dengan manuver jaringan yaitu masuk LBS Ngis (penyulang Tejakula). Selanjutnya melepas LBS Kebon dilanjutkan dengan melepas LBS Datah. Langkah berikutnya adalah melakukan potong jaringan setelah AB0016. Tindakan manuver jaringan dilakukan untuk melokalisir daerah padam diseputaran titik potong rekonfigurasi jaringan penyulang Abang. 


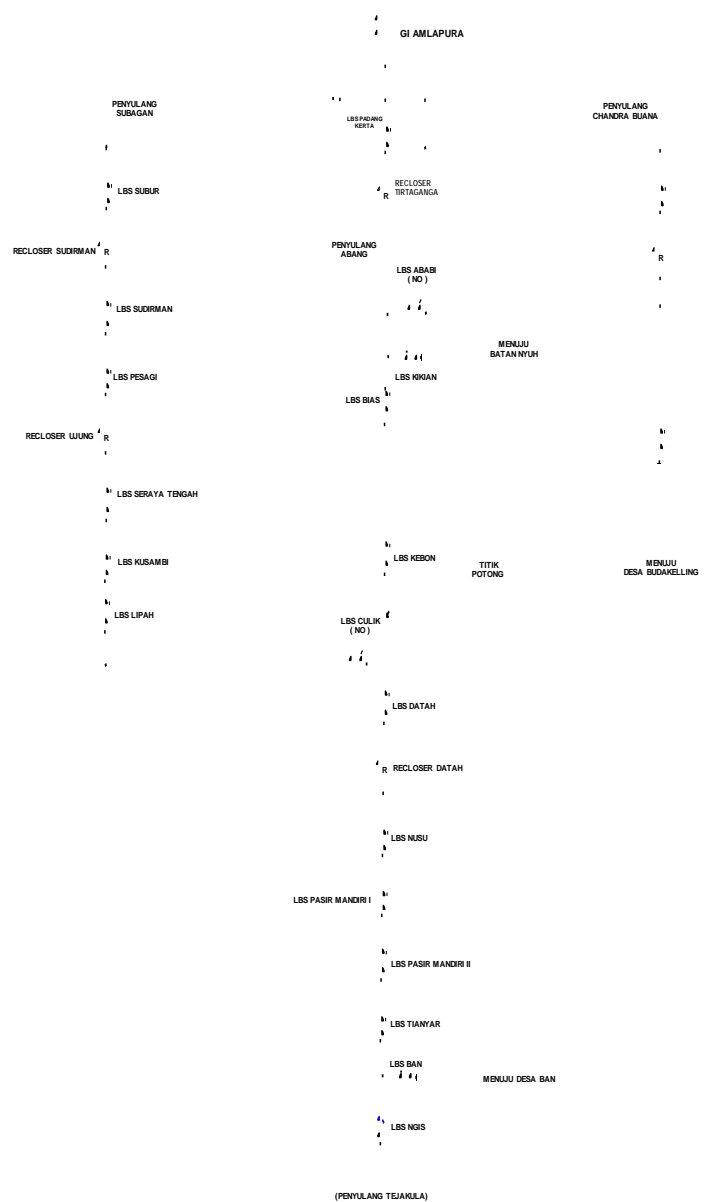

Gambar 7. Single Line Diagram Penyulang Abang dan Penyulang Subagan

4.3.1 Jatuh Tegangan Penyulang Abang Setelah Direkonfigurasi Dengan Pemotongan Jaringan

Hasil running program ETAP setelah dilakukan pemotongan jaringan penyulang Abang untuk pemindahan sebagian beban diperoleh hasil untuk tegangan terendahnya sebesar 19,39 kV pada bus 189.

$$
\begin{gathered}
(\%)=\frac{\text { Teg Sumber }- \text { Teg Terendah }}{\text { Teg Sumber }} \times 100 \% \\
=\frac{20-19,39}{20} \times 100 \% \\
=3,05 \%
\end{gathered}
$$

\subsubsection{Rugi-Rugi Daya Penyulang Abang Setelah Direkonfigurasi Dengan Pemotongan Jaringan}

Analisa rugi-rugi daya pada penyulang Abang menggunakan software ETAP dengan memasukan data bus, data kapasitas trafo, data beban trafo, serta data penghantar. Hasil running program ETAP penyulang Abang setelah direkonfigurasi dengan pemotongan jaringan diperoleh total rugi-rugi daya sebesar 109,7 kW

(\%)

$$
\begin{gathered}
=\frac{109,7}{3142} \times 100 \% \\
=3,49 \%
\end{gathered}
$$

\subsubsection{Jatuh Tegangan Penyulang \\ Subagan Setelah Direkonfigurasi Dengan Pemotongan Jaringan}

Rekonfigurasi dengan pemotongan jaringan penyulang Abang untuk penyaluran sebagaian beban penyulang Abang ke penyulang Subagan mengakibatkan jatuh tegangan peyulang Subagan menjadi besar. Hasil running program ETAP untuk tegangan terendahnya diperoleh hasil pada bus 190 sebesar $14,477 \mathrm{kV}$.

$$
\begin{gathered}
(\%)=\frac{\text { Teg Sumber }- \text { Teg Terendah }}{\text { Teg Sumber }} \times 100 \% \\
=\frac{20-14,477}{20} \times 100 \% \\
=27,615 \%
\end{gathered}
$$

\subsubsection{Rugi-Rugi Daya Penyulang Subagan Setelah Direkonfigurasi Dengan Pemotongan Jaringan}

Rugi-rugi daya penyulang Subagan setelah direkonfigurasi dengan penyulang Abang diperoleh hasil dari running program ETAP sebesar $973,5 \mathrm{~kW}$.

$$
\begin{gathered}
(\%)=\frac{\text { Rugi }- \text { Rugi Daya }}{\text { Daya } \text { Tersalurkan }} \times 100 \% \\
=\frac{973,5}{7330} \times 100 \% \\
=13,28 \%
\end{gathered}
$$

\subsection{Rekonfigurasi Penyulang Abang Dengan Perencanaan Penyulang Baru}

Perencanaan penyulang baru didasari oleh berbagai indikator seperti jatuh tegangan, rugi-rugi daya serta beban yang dipikul oleh penyulang. Sesuai dengan Master Plan System Distribution (MPSD) PLN Distribusi Bali dijelaskan tentang jatuh tegangan diharapkan tidak di bawah $19 \mathrm{kV}$, rugi-rugi daya tidak melebihi $6 \%$ serta beban yang dipikul oleh penyulang tidak melebihi 150 ampere. Penyulang baru akan diberikan nama penyulang Kubu sesuai dengan nama daerah yang dilayani oleh penyulang tersebut. Gambar 8 merupakan single line perencanaan penyulang Kubu. 


\subsubsection{Rancangan Anggara Biaya Penyulang Kubu}

Realisasi penyulang baru untuk menunjang kinerja unit dalam meningkatkan kualitas pelayanan terhadap pelanggan. Dalam merealisasikan ini maka akan dirancang anggaran atau biaya untuk hal tersebut. Rancangan anggaran biaya (RAB) merupakan segala bentuk perencanaan mengenai aktivitas-aktivitas perusahaan yang dinyatakan dalam satuan uang. Adapun RAB perencanaan penyulang Kubu ditunujukan pada Tabel 1:

Tabel 1. RAB Penyulang Kubu

\begin{tabular}{|c|c|}
\hline Uraian Pekerjaan & Biaya \\
\hline Pemasangan MVTIC & Rp. 591,973,315 \\
\hline
\end{tabular}

\begin{tabular}{|c|l|}
\hline Pemasangan SKTM & Rp. 59,276,722 \\
\hline Total & Rp. 651.250.037 \\
\hline
\end{tabular}

\subsubsection{Jatuh Tegangan Penyulang Kubu} Hasil Running Program ETAP

Hasil perencanaan penyulang Kubu untuk memperbaiki jatuh tegangan penyulang Abang dapat dilihat dengan menjalankan program ETAP. Tegangan terendah penyulang Kubu diperoleh sebesar 19,41 kV pada bus 357 .

$$
\begin{gathered}
(\%)=\frac{\text { Teg Sumber }- \text { Teg Terendah }}{\text { Teg Sumber }} \times 100 \% \\
=\frac{20-19,41}{20} \times 100 \% \\
=2,95 \%
\end{gathered}
$$

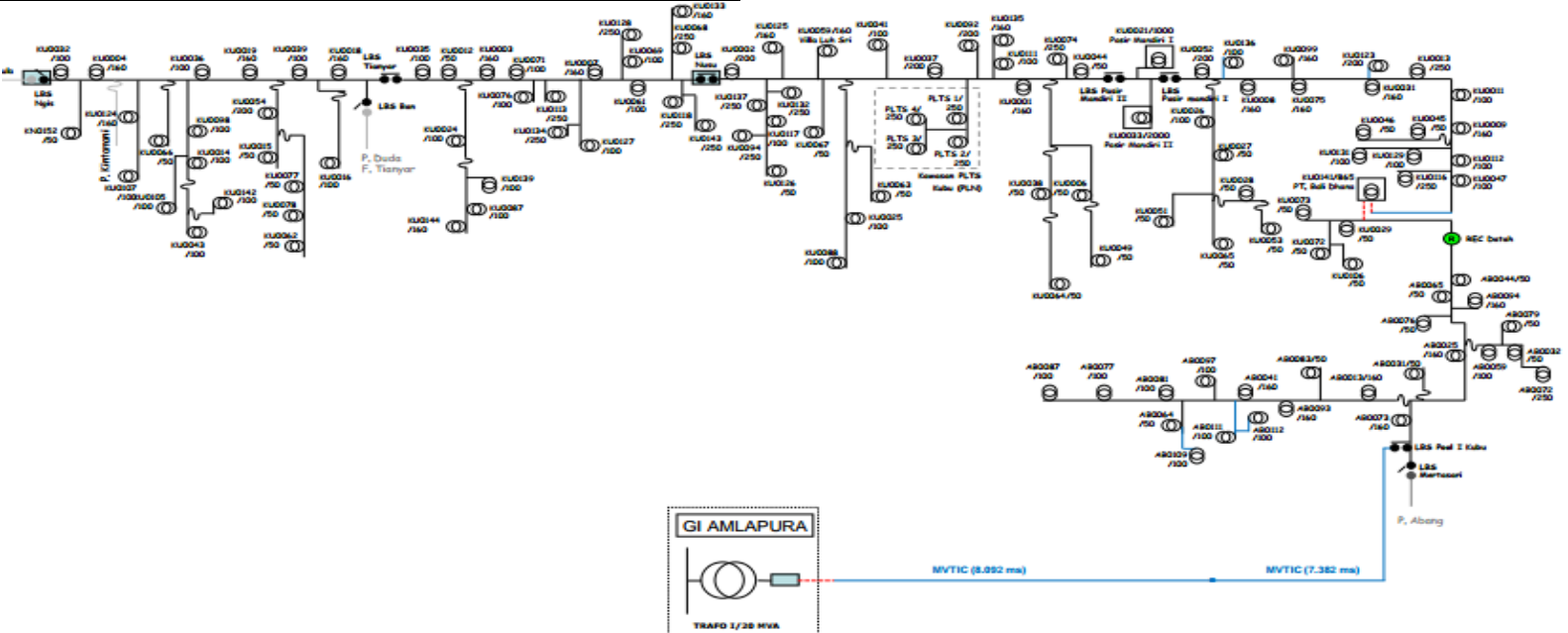

Gambar 8. Single Line Perencanaan Penyulang Kubu

\subsubsection{Rugi-Rugi Daya Penyulang Kubu Hasil Running Program ETAP}

Rugi-rugi daya penyulang Kubu diperoleh dari hasil running program ETAP sebesar 100,5 kW.

$$
\begin{aligned}
(\%) & =\frac{\text { Rugi }- \text { Rugi Daya }}{\text { Daya Tersalurkan }} \times 100 \% \\
& =\frac{100,5}{3676} \times 100 \% \\
& =2,73 \%
\end{aligned}
$$

\subsubsection{Hasil Analisa Penyulang Abang Saat Beroperasinya Penyulang Kubu}

Beban yang tersalurkan oleh penyulang Abang setelah dilakukan pemindahan beban penyulang Abang kepenyulang Kubu menjadi $3.080 \mathrm{~kW}$ dengan total transformator sejumlah 69 unit dan jenis penghantar tetap menggunakan konduktor AAAC $150 \mathrm{~mm}^{2}$.

\subsubsection{Jatuh Tegangan Penyulang Abang Setelah Direkonfigurasi Dengan Penyulang Kubu}

Jatuh tegangan terendah penyulang Abang setelah direkonfigurasi dengan penyulang Kubu sebesar 19,412 kV pada bus 188. Hasil jatuh tegangan menggunakan program ETAP.

$$
\begin{gathered}
(\%)=\frac{\text { Teg Sumber }- \text { Teg Terendah }}{\text { Teg Sumber }} \times 100 \% \\
=\frac{20-19,412}{20} \times 100 \% \\
=2,94 \%
\end{gathered}
$$

4.4.6 Rugi-Rugi Daya Penyulang Abang Setelah Direkonfigurasi Dengan Penyulang Kubu

Hasil perhitungan program ETAP untuk rugi-rugi daya penyulang Abang setelah 
direkonfigurasi dengan penyulang Kubu sebesar 105,2 kW.

$$
\begin{aligned}
(\%) & =\frac{\text { Rugi }- \text { Rugi Daya }}{\text { Daya Tersalurkan }} \times 100 \% \\
& =\frac{105,2}{3080} \times 100 \% \\
& =3,41 \%
\end{aligned}
$$

\subsection{Analisa Sebelum dan Sesudah Rekonfigurasi}

Tabel 2 adalah hasil perbandingan tegangan terendah dan rugi-rugi daya pada penyulang Abang dengan menggunakan rekonfigurasi jaringan dengan pemotongan dan rekonfigurasi jaringan dengan perencanaan penyulang baru

\begin{tabular}{|c|c|c|c|c|c|c|c|}
\hline \multirow{3}{*}{$\begin{array}{l}\mathrm{N} \\
0\end{array}$} & \multirow{3}{*}{$\begin{array}{l}\text { Nama } \\
\text { Penyulang }\end{array}$} & \multirow{2}{*}{\multicolumn{2}{|c|}{ Sebelum Rekonfigurasi }} & \multicolumn{4}{|c|}{ Setelah Rekonfigurasi Jaringan } \\
\hline & & & & \multicolumn{2}{|c|}{ Pemotongan Jaringan } & \multicolumn{2}{|c|}{$\begin{array}{c}\text { Perencanaan Penyulang } \\
\text { Baru }\end{array}$} \\
\hline & & $\begin{array}{c}\text { Jatuh } \\
\text { Tegangan }\end{array}$ & $\begin{array}{c}\text { Rugi-Rugi } \\
\text { Daya }\end{array}$ & $\begin{array}{c}\text { Jatuh } \\
\text { Tegangan }\end{array}$ & $\begin{array}{l}\text { Rugi-Rugi } \\
\text { Daya }\end{array}$ & $\begin{array}{c}\text { Jatuh } \\
\text { Tegangan } \\
\end{array}$ & $\begin{array}{c}\text { Rugi-Rug } \\
\text { Daya } \\
\end{array}$ \\
\hline 1 & Abang & $16.255 \%$ & $10.12 \%$ & $3.05 \%$ & $3.49 \%$ & $2.94 \%$ & $3,41 \%$ \\
\hline 2 & Subagan & $6.78 \%$ & $3.89 \%$ & $27.615 \%$ & $13.28 \%$ & - & - \\
\hline 3 & Kubu & - & - & - & . & $2,95 \%$ & $2.73 \%$ \\
\hline
\end{tabular}

Tabel 2. Tabel Perbandingan Sebelum dan Sesudah Rekonfigurasi

Dari Tabel 2 menunjukkan bahwa penyulang Abang yang awalnya memiliki persentase jatuh tegangan sebesar 16,255\% dan rugi-rugi daya sebesar 10,12\% setelah direkonfigurasi dengan penyulang Subagan melalui pemotongan jaringan mampu memperbaiki persentase jatuh tegangan dan rugi-rugi daya menjadi sebesar $3,05 \%$ dan $3,49 \%$. Sedangkan, hasil rekonfigurasi untuk penyulang Subagan menunjukkan kinerja yang buruk untuk persentase jatuh tegangan dan rugi-rugi daya yang awalnya $6,78 \%$ dan $3,89 \%$ menjadi $27,615 \%$ dan $13,28 \%$. Hal tersebut disebabkan beban yang dipikul oleh penyulang Subagan menjadi lebih besar dari sebelumnya.

Rekonfigurasi dengan perencanaan penyulang Kubu menunjukkan dampak yang positif untuk penyulang Abang, yang awalnya memiliki persentase jatuh tegangan sebesar $16,255 \%$ dan rugi-rugi daya sebesar 10,12\% menjadi $2,94 \%$ dan $3,41 \%$. Sesuai dengan hasil running program ETAP dampak positif juga ditunjukan oleh penyulang Kubu dengan persentase jatuh tegangan sebesar 2,95\% dan rugi-rugi daya sebesar 2,73\%. Hasil tersebut sudah sesuai dengan ketentuan SPLN No. 72 Tahun 1987 tentang toleransi tegangan yang diijinkan serta sesuai dengan MPSD PLN distribusi Bali yaitu rugi-rugi daya tidak lebih dari 6\%. Sehingga, dalam rekonfigurasi penyulang Abang langkah yang paling tepat dilakukan adalah dengan cara perencanaan penyulang Kubu dilihat dari hasil yang sudah diperoleh.

\section{KESIMPULAN DAN SARAN 5.1 Kesimpulan}

Dari penjelasan hasil dan pembahasan maka dapat diperoleh simpulan yaitu sebelum direkonfigurasi penyulang Abang memiliki tegangan terendah sebesar $16,749 \mathrm{kV}$ atau sebesar $16,255 \%$ dan rugi-rugi daya sebesar $573,7 \mathrm{~kW}$ atau sebesar 10,12\%. Rekonfigurasi dengan cara pemotongan jaringan penyulang Abang diawali dengan melihat kondisi eksisting serta single line diagram penyulang Abang. Penyulang Abang yang dipotong sebelah utara gardu AB0016 mempunyai tegangan terendah sebesar 19,39 kV atau sebesar 3,05\% dan rugi-rugi daya 109,7 kW atau sebesar 3,49\%. Akibat pemindahan beban penyulang Abang ke penyulang Subagan mengakibatkan penyulang Subagan memiliki tegangan terendah sebesar 14,477 kV atau sebesar 27,615\% dan rugi-rugi daya yang awalnya sebesar $175,6 \mathrm{~kW}$ menjadi $973,5 \mathrm{~kW}$ atau sebesar 13,28\%. Rekonfigurasi dengan perencanaan penyulang baru untuk menurunkan jatuh tegangan dan rugi-rugi daya penyulang Abang. Penyulang Kubu ini akan memiliki RAB sebesar Rp. 651.250.037. Penyulang Abang yang awalnya memiliki tegangan terendah sebesar 16,749 kV dengan beroperasinya penyulang Kubu, terjadinya kenaikan persentase tegangan menjadi $19,412 \mathrm{kV}$ atau sebesar 2,94\% dan rugi-rugi daya yang awalnya 573,7 kW menjadi 105,2 kW atau sebesar 3,41 \%. Sedangkan, penyulang Kubu akan memiliki tegangan terendah 19,41 kV atau sebesar 2,95 \% dan rugi-rugi daya $105,2 \mathrm{~kW}$ atau sebesar 2,73\%. Dari hasil rekonfigurasi tersebut dapat dilihat hasil yang paling baik yaitu dengan perencanaan penyulang Baru

\subsection{Saran}

Berdasarkan penelitian yang telah dilakukan, maka terdapat saran untuk meningkatkan penelitian ini yaitu agar PT PLN (Persero) Area Bali Timur tetap memperhatikan perkembangan beban pada penyulang Kubu karena penyulang Kubu akan memikul setengah beban penyulang Abang kondisi awal. 


\section{DAFTAR PUSTAKA}

[1] R Julen Kartoni, Edy Ervianto. 2016. Analisa Rekonfigurasi Pembebanan Untuk Mengurangi Rugi-Rugi Daya Pada Saluran Distribusi 20 kV (jurnal). Universitas Riau.

[2] Swastawa, I Nyoman. 2011. Analisa Keandalan Penyulang Buduk Setelah Rekonfigurasi Jaringan (jurnal). Program Studi Teknik Elektro Fakultas Teknik Universitas Udayana.

[3] Panji Pradipta, 2006. Analisa Keandalan Penyulang 20 kV Pada Area Jaringan Bali Timur (jurnal). Program Studi Teknik Elektro. Fakultas Teknik Universitas Udayana.

[4] Suswanto, Daman. 2009. Sistem Distribusi Tenaga Listrik (jurnal). Padang. Universitas Negeri Padang.

[5] Suhadi dan Tri Wrahatnolo. 2008. Teknik Distribusi Tenaga Listrik Jilid I. Jakarta: Departemen Pendidikan Nasional.

[6] Zebua, Osea dan I Made Ginarsa. 2016. Rekonfigurasi Jaringan Distribusi Untuk Meminimisasi Rugi-Rugi Pada Penyulang Kabut Di Gardu Induk Teluk Betung Menggunakan Metode Binary Particle Swarm Optimization (BPSO)(jurnal). Jurnal Nasional Teknik Elektro, Vol:5,No.1.

[7] Tanjung, Abrar. 2014. Rekonfigurasi Sistem Distribusi 20 KV Gardu Induk Teluk Lembu Dan PLTMG Langgam Power Untuk Mengurangi Rugi Daya Dan Drop Tegangan.(jurnal). Rumbai:Jurnal Sains, Teknologi dan Industri, Vol. 11, No 2.

[8] Suyanto, Ary. 2010. Rekonfigurasi Jaringan Distribusi 20 kV pada Penyulang Buduk(jurnal). Program Studi Teknik Elektro. Universitas Udayana. 